of a social worker to help the medical teams because every patient does not need to see one and social workers are too few to make such a scheme generally applicable. We have since adopted a policy in which the medical teams assess patients initially and ask for advice from psychiatrists and social workers as necessary.

Now that about one in seven ${ }^{1314}$ of all acute medical admissions are for self-poisoning, it is increasingly impracticable for each of them to receive a specialist psychiatric evaluation. This policy ${ }^{2}$ has discouraged the training of our future doctors and nurses because it relies so much on specialist advice. Consequently, many doctors who will later have to evaluate suicidal risk and decide whether or not to prescribe for psychologically distressed patients may be ill-equipped to do so. There is another reason why the management of attempted suicides in the general hospital is of such importance in medical education. As Stenge ${ }^{15}$ pointed out, trainee doctors and nurses can be shown that to preserve life they must concern themselves not only with their patients' physical condition, but also with their psychological and social problems.

We conclude that there is a strong case for amending the recommendation in the Hill Report ${ }^{2}$ so that physicians may decide in each case of deliberate self-poisoning whether a psychiatric opinion is necessary. A selective approach would allow scarce specialist resources to be used more effectively. Psychiatrists might teach junior staff to assess these patients and might concentrate more on improving the treatment and aftercare services, perhaps by organising them by districts. Increasing attention to medical education in this field would contribute to the general training of doctors and nurses, as well as to the prevention of poisoning.

This project (No 79/80) was financed by the East Anglian Regional Health Authority. We thank the consultant physicians at Addenbrooke's Hospital and the consultant psychiatrists at Fulbourn Hospital for permission to interview their patients; the nursing staff at Addenbrooke's, particularly Sister P Mountford, for their participation; general practitioners for completing questionnaires; and Professor I H Mills for his advice and comments.
Medical teams: Drs K Ashley, S Atkinson, S Birch, C Bowman, T C Chalmers, $S$ Chinnock Jones, $N$ Choudhary, $M$ F Chung, $P$ J Ciclitira, J C Cormack, M Couriel, P Crouch, M Davie, A Davies, $M K$ Davies, R G Dent, A P Dick, O M Edwards, D B Evans, M J Farthing, A Ford, M Gawel, J O Hunter, J R Jenner, R J Jung, R Kirby, R Machell, B McLeod, N I McNeill, N J McPherson, W M Malcolm, D Marsh, H Mason, L C Martin, B E Monk, C Olczak, R Peacock, R C Pletts, P Plowman, T B Rosenbaum, $P$ Rowan, E Rowland, C Royce, D Rubinstein, $M$ Rudolf, S H Sachs, P Salt, B Sandhu, M Shooter, A Soulati, J Stuart, S A Tomlinson, $J$ Treleaven, $M$ Whalley, $M$ Wheeler, $N$ Wickham, S Wilkinson, Professor I H Mills.

Psychiatrists on rota: Drs D H Clark, B W Davy, O E F Hodgson, J McKeown, A R K Mitchell, D J Muller, G M Petrie, J M Werner, J C Wilkinson, $R$ W Williams, $R$ Young, B B Zeitlyn.

Psychiatrists in "special" clinic: G R Nayani and R W Williams.

\section{References}

${ }^{1}$ Ministry of Health, HM (61), 94.

2 Central and Scottish Health Services Councils, Hospital Treatment of Acute Poisoning. London, HMSO, 1968.

${ }^{3}$ Kennedy, P, and Kreitman, N, British Fournal of Psychiatry, 1973, 123, 23.

${ }^{4}$ Greer, S, and Bagley, C, British Medical fournal, 1971, 1, 310.

${ }^{5}$ Collier, J, Cummins, T A, and Hamilton, M, fournal of the Royal College of Physicians, 1976, 10 (4), 381.

${ }^{6}$ Schmidt, E H, O'Neal, P, and Robins, E, Fournal of the American Medical Association, 1954, 155 (6), 549.

'Retterstol, N, Life-Threatening Behaviour, 1974, 4 (4), 203.

${ }^{8}$ Welu, T C, and Picard, K M, Proceedings of the 7th International Conference for Suicide Prevention, p 447. Amsterdam, Swets and Zeitlinger, BV, 1974.

${ }^{9}$ Crammer, J L, British Medical fournal, 1969, 2, 651.

1" Sainsbury, P, Medicine, 1974, 30, 1772

11 Patel, A R, British Medical fournal, 1975, 2, 426.

12 Ramon, S, Bancroft, J H J, and Skrimshire, A M, British fournal of Psychiatry, 1975, 127, 257.

${ }^{13}$ Lawson, A A H, and Mitchell, I, British Medical fournal, 1972, 4, 153.

${ }^{14}$ Mills, I H, and Eden, M A M, in Man in Urban Environments, ed G A Harrison and J B Gibson. London, Oxford University Press, 1976.

15 Stengel, E, in Suicidal Behaviours, ed H L P Resnick. London, J and A Churchill Ltd, 1968.

(Accepted 18 October 1977)

\title{
Leucocytosis is not a manifestation of rejection
}

\author{
A S DAAR, P J MORRIS, D O OLIVER
}

British Medical fournal, 1977, 2, 1570-1571

\section{Summary}

The leucocyte response to allograft rejection was retrospectively analysed in 80 rejection episodes that occurred in 50 patients. There was no significant change in leucocyte count in 32 rejection episodes. In 27 there was a fall

\footnotetext{
Nuffield Department of Surgery, University of Oxford, Radcliffe Infirmary, and Transplant Unit, Churchill Hospital, Oxford A S DAAR, MRCP, senior house officer P J MORRIS, PHD, FRCS, Nuffield professor of surgery D O OLIVER, FRCP, consultant physician
}

\begin{abstract}
in leucocyte count of more than $20 \%$ and in only 21 was there a rise in count of more than $20 \%$.

Thus leucocytosis seems not to be a manifestation of rejection; indeed, it is the least common response, a fall in the count being commoner. The results also suggest that the prognosis for the graft is poorer when the leucocyte count falls significantly.
\end{abstract}

\section{Introduction}

It has been suggested for many years that leucocytosis is a manifestation of acute rejection. ${ }^{1-3}$ Others, however, have not found a constant association ${ }^{4}$ and Bastle et al ${ }^{5}$ have recently shown, in a study of 159 rejection episodes, that leucocytosis is the least common finding in rejection and that a fall in the leucocyte count, often to leucopenic levels, is a common response. For these reasons we evaluated the leucocyte response to rejection 
retrospectively in 80 definite rejection episodes that occurred in 50 patients.

\section{Patients and methods}

Forty-four patients received cadaveric grafts and six received grafts from living related donors. The 80 definite rejection episodes occurred from four to 315 days after transplantation. Acute rejection was defined as a deterioration in renal function indicated by a rise in serum creatinine concentration of $20 \%$ or more in the absence of any other cause of changed renal function. A fall in the urine output, fever, hypertension, or swelling and tenderness of the graft were not always associated with the diminution of renal function. Histological examination of graft biopsy and nephrectomy specimens confirmed the presence of rejection in 20 of these rejection episodes.

After transplantation azathioprine was given in a dose of $2-2.5 \mathrm{mg}$ / $\mathrm{kg}$ or in a lower dose if there was leucopenia. Oral prednisolone was started at $100 \mathrm{mg} /$ day and was reduced by $5 \mathrm{mg} /$ day on every sixth day to $20 \mathrm{mg} /$ day and then reduced by $1 \mathrm{mg}$ every two weeks until the maintenance dose of $10 \mathrm{mg} /$ day was reached. Rejection episodes were treated by three intravenous bolus injections of methylprednisolone, $1 \mathrm{~g}$ every 12 hours, or in a few cases by an increased oral dose of prednisolone. Fourteen of these $80(18 \%)$ rejections could not be reversed by treatment and resulted in loss of the graft.

Full blood counts, serum creatinine concentration, and other indices of graft function were measured daily during the first month after operation and then less often unless there was leucopenia or deteriorating graft function. The baseline prerejection leucocyte count was taken as the average of at least three counts while the patient was on a stable dose of azathioprine without evidence of rejection or other conditions, such as infections, that might have altered peripheral blood leucocyte counts. The rejection count was the value determined on the day of diagnosis of rejection but before starting treatment. The leucocyte responses were classified according to percentage change in the count, with a change of $20 \%$ or more being considered significant. The rejection episodes therefore fell into three groups according to whether the leucocyte count showed an increase of over $20 \%$, no significant change, or a fall of over $20 \%$

\section{Results}

We found that only $21(26 \%)$ of the rejection episodes were associated with an increase in leucocyte count, while $32(40 \%)$ were associated with no significant change and $27(34 \%)$ were associated with a significant fall in leucocyte count. The incidence of graft loss due to rejection was highest among the episodes associated with a fall in leucocyte count $(7(26 \%)$ out of 27$)$ and lowest among those associated with no significant change $(3(9 \%)$ out of 32$)$; grafts were lost in $4(19 \%)$ of the 21 episodes in which the leucocyte count rose. None of these incidences were significantly different from each other

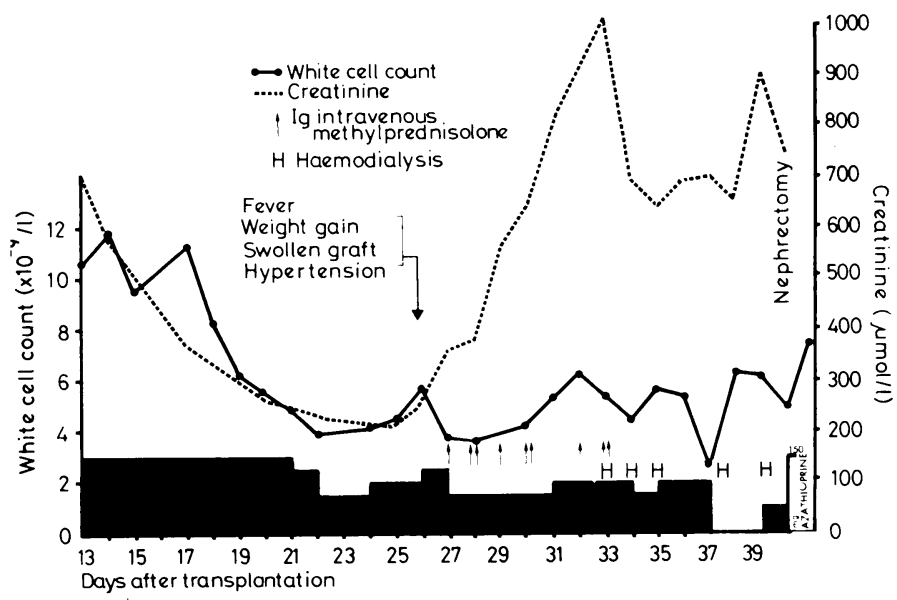

Rejection episode in one patient, illustrating onset of leucopenia before clinical diagnosis of acute rejection.

Conversion: SI to traditional units-Plasma Creatinine: $1 \mu \mathrm{mol} / 1 \approx 0.0113 \mathrm{mg}$ / $100 \mathrm{ml}$. Leucocyte count: $1 \times 10^{9} / \mathrm{l} \approx 1000 / \mathrm{mm}^{3}$.
( $\%^{2}$ with Yates correction factor), but they do not conflict with the observation of Bastle et al that the highest incidence of graft loss was in those episodes associated with a significant decrease in leucocyte count.5

An example of leucopenia associated with rejection is illustrated in the figure, which shows the course of rejection in a patient who received a graft from a 3-year-old donor. After transplantation there was a period of tubular necrosis treated by dialysis until the serum creatinine concentration fell spontaneously on the 13th day. The leucocyte count, which was $9 \cdot 5-10.8 \times 10^{9} / 1$, fell rapidly on the 18 th day and thereafter remained at 3.6-6.2 $\times 10^{9} / 1$ despite a reduction in the dose of azathioprine. The serum creatinine concentration, however, continued to fall until the 25 th day. Rejection was diagnosed on the 27th day and the patient was treated with intravenous methylprednisolone, but graft function continued to deteriorate despite two further courses of treatment. Graft nephrectomy was performed on the 40th day and histological examination confirmed severe rejection.

\section{Discussion}

It has been suggested that leucopenia in association with some rejection episodes may be due to vigorous antirejection treatment. We think this is unlikely because leucopenia often precedes treatment and the dose of azathioprine is not increased during rejection. Furthermore, the effective dose of azathioprine is not increased at the time of rejection, as the biological activity of azathioprine is not changed by impaired renal function. ${ }^{6}$ And large doses of steroids tend to cause leucocytosis rather than leucopenia.

A more likely explanation of the fall in leucocyte count is the rejection process itself. Although rejection is classically considered to be a manifestation of cell-mediated immunity, it is now appreciated that humoral mechanisms and immunologically non-specific cells such as leucocytes and platelets play an important part in mediating graft damage. Thus the histological picture of rejection may range from a cellular infiltrate consisting mainly of mononuclear cells to one containing neutrophils? and even basophils ${ }^{\star}$ in addition to mononuclear cells.

In the immunosuppressed patient the bone marrow may already have borderline reserves and the severe systemic manifestations that often accompany acute rejection may cause further toxic suppression. Under these circumstances margination or consumption of leucocytes in the rejecting graft might conceivably lead to a fall in the peripheral leucocyte count. Thus it seems that not only do leucocytes play a critical part in the pathogenesis of acute rejection but the rejection process itself might be responsible for the fall in leucocyte count. Our results have led us to the conclusion that, contrary to common belief, leucocytosis is the least common response to acute allograft rejection. A fall in the leucocyte count is commoner, and analysis of the incidence of graft loss would suggest that the individual graft prognosis may be poorer when there is a significant decrease in the leucocyte count.

This work was supported in part by a grant from the Medical Research Council.

\section{References}

${ }^{1}$ Murray, J E, et al, New England fournal of Medicine, 1963, 268, 1315.

Starzl, T E, Experience in Renal Transplantation, p 135. Philadelphia, Saunders, 1964

${ }^{3}$ Morris, P J, in Renal Disease, ed D Black, 4th edn. Oxford, Blackwell. In press.

${ }^{4}$ Hamburger, J, et al, Renal Transplantation, Theory and Practice, p 178. Baltimore, Williams and Wilkins, 1972.

${ }^{5}$ Bastle, C P, Hendler, E D, and Finkelstein, F O, Clinical Nephrology, 1975, 4, 228.

${ }^{6}$ Bach, J F, and Dardenne, M, Transplantation, 1971, 12, 253.

' Herbertson, B M, in Immunological Aspects of Transplantation Surgery, ed R Calne, p 4. Lancaster, Medical and Technical Publishing, 1973. ${ }^{8}$ Colvin, R B, and Dvorak, H F, Lancet, 1974, 1, 212.

(Accepted 6 October 1977) 